University of Nebraska - Lincoln

DigitalCommons@University of Nebraska - Lincoln

Sociology Department, Faculty Publications

Sociology, Department of

1999

\title{
A Risk-Amplification Model of Victimization and Depressive Symptoms Among Runaway and Homeless Adolescents
}

\author{
Les B. Whitbeck \\ University of Nebraska-Lincoln, Iwhitbeck2@unl.edu \\ Dan R. Hoyt \\ University of Nebraska-Lincoln, dhoyt2@unl.edu \\ Kevin Yoder \\ lowa State University
}

Follow this and additional works at: https://digitalcommons.unl.edu/sociologyfacpub

Part of the Sociology Commons

Whitbeck, Les B.; Hoyt, Dan R.; and Yoder, Kevin, "A Risk-Amplification Model of Victimization and Depressive Symptoms Among Runaway and Homeless Adolescents" (1999). Sociology Department, Faculty Publications. 72.

https://digitalcommons.unl.edu/sociologyfacpub/72

This Article is brought to you for free and open access by the Sociology, Department of at DigitalCommons@University of Nebraska - Lincoln. It has been accepted for inclusion in Sociology Department, Faculty Publications by an authorized administrator of DigitalCommons@University of Nebraska - Lincoln. 
Published in American Journal of Community Psychology 27:2 (1999), pp. 273-296. Copyright (C) 1999 Plenum Publishing Corporation/Springer Verlag. Used by permission. http://www.springerlink.com/content/t37813v68410h111/

The Midwest Homeless and Runaway Adolescent Project is supported by the National Institute of Mental Health (MH50140).

\title{
A Risk-Amplification Model of Victimization and Depressive Symptoms Among Runaway and Homeless Adolescents
}

\author{
Les B. Whitbeck, Dan R. Hoyt, and Kevin A. Yoder \\ Institute for Social and Behavioral Research, \\ Department of Sociology, Iowa State University \\ Corresponding author - L. B. Whitbeck
}

\begin{abstract}
This report is an examination of a theoretical model of risk amplification within a sample of 255 homeless and runaway adolescents. The young people were interviewed on the streets and in shelters in urban centers of four Midwestern states. Separate models were examined for males $(n=102)$ and females $(n=153)$. Results indicated that street experiences such as affiliation with deviant peers, deviant subsistence strategies, risky sexual behaviors, and drug and/or alcohol use amplified the effects of early family abuse on victimization and depressive symptoms for young women. These street adaptations significantly increased the likelihood of serious victimization over and above the effects of early family history for both young men and women. Similarly, street behaviors and experiences increased the likelihood of depressive symptoms for young women over the effects of early family abuse, but not for young men. The risk-amplification model from the life course theoretical perspective is discussed as an example of the cumulative continuity of maladaptive behaviors.
\end{abstract}

Keywords: runaways, homeless adolescents, victimization, depression

Although conservative estimates indicate that about 500,000 (Finkelhor, Hotaling, \& Sedlak, 1990) to 1 million (Committee on Labor and Human Resources, 1990) adolescents run away from home each year 
and that there are 127,000 "throwaway" adolescents (Finkelhor et al., 1990) on the streets of our cities, we know relatively little about these high-risk young people. Because of the difficulties in studying this population, existing research often has been based on small samples from shelters located in one large urban area. Research, to date, has focused primarily on prevalence reports, causes of running away, and street experiences of homeless and runaway adolescents (for reviews see: Robertson, 1992; Rotheram-Borus, Parra, Cantwell, Gwadz, \& Murphey, 1996). Little, if any, theoretical progress has been made addressing the behavioral and psychological effects of early independence on adolescent development.

In this paper a theoretical model of developmental risk is examined using data from an ongoing research project involving interviews with homeless and runaway adolescents in Missouri, Iowa, Nebraska, and Kansas. The proposed model is based on life course developmental theory (Elder, 1997) and social interaction theory (Patterson, 1982). It addresses the mechanisms through which street experiences amplify negative developmental effects originating in the family. From this perspective, interaction styles and behavioral patterns that originate in coercive-aggressive family processes are continually reinforced during periods of independence via "coercive chains" of negative interactions (Patterson, 1982) and mutual exploitation. These negative street experiences exacerbate and crystallize existing psychological problems. The developmental effects of early negative family interactions are carried into the streets by runaway adolescents and result in nonconventional peer associations and deviant behaviors that increase risk for physical and sexual victimization (Whitbeck, Hoyt, \& Ackley, 1997a; Whitbeck \& Simons, 1990,1993). These street associations and experiences, in turn, accentuate psychological distress.

\section{Theoretical Background}

It is generally accepted that the majority of runaway and homeless adolescents leave troubled, often physically and/or sexually abusive, families. Although rates of adolescent reports of abusive family backgrounds vary widely across studies, they all indicate severe risk for physical and sexual abuse. Janus, Burgess, and McCormack (1987) found that $71.5 \%$ of the male runaways they interviewed reported physical abuse, and $38.2 \%$ reported sexual abuse from families of origin. Silbert and Pines' (1981) study of juvenile and adult street prostitutes indicated that $60 \%$ had been sexually abused by adult caretakers. In the Kurtz, Kurtz, and Jarvis (1991) report, based on shelter intake records of 2,019 runaways from eight southeastern states, $28 \%$ of the runaways 
identified themselves as having been in sexually or physically abusive families. About 30\% of Kufeldt and Nimmo's (1987) sample of 474 runaways reported family physical abuse. Bridge Inc., in Boston, reported a $65 \%$ physical abuse rate (Saltonstall, 1984); only $5 \%$ of their sample "clearly stated there was no abuse in their homes" (p. 78). A Los Angeles County shelter/drop-in center study (Pennbridge, Yates, David, \& Mackenzie 1990) reported a $47 \%$ abuse/neglect rate. Using the Conflict Tactics Scale (CTS) developed by Straus and Gelles (1990), Whit- beck and Simons (1993) reported physical abuse rates ranging from $80 \%$ for slapping to $48 \%$ for being "beat up" for a sample of 150 street youth in Des Moines. Thirty-seven percent of the young women reported forced sexual activity by an adult caretaker.

More recent research conducted by Whitbeck, Hoyt, and Ackley (1997b) indicated virtual concurrence between parents/caretakers' reports and the adolescents' reports on less severe levels of physical abuse on the CTS (e.g., pushed or shoved in anger, slapping face or head). Although reports of parents/caretakers and runaway adolescents diverged on measures of more severe violence, parents/caretakers reported 16\% of the adolescent boys and 10\% of adolescent girls had been beaten with fists. In addition, parents/caretakers reported 15\% of girls had been sexually abused (Whitbeck et al., 1997b).

Besides high rates of parent/caretaker and adolescent reported abuse, homeless and runaway adolescents and their parents/caretakers rate their families as more dysfunctional than do nonrunaways. Whitbeck and colleagues found that the parent/caretakers of runaway adolescents rated themselves lower on measures of parental monitoring and parental warmth and supportiveness and higher on measures of parental rejection relative to parents of similarly aged nonrunaway adolescents from the same geographical region in single-parent and intact two-parent families. Runaway adolescents also scored their parents/caretakers lower on each of these measures than did nonrunaway adolescents of similar age in two-parent or single-parent families. Schweitzer, Hier, and Terry (1994) found that homeless adolescents scored higher than housed children on measures of deprivation based on the Parental Bonding Inventory (Parker, Tupling,\& Brown, 1979) and the Family Environment Scale (Moos \& Moos, 1981). Controlled studies also indicate that homeless adolescents report higher levels of parent marital discord and lower levels of parental care and acceptance than adolescents remaining at home (Daddis, Braddock, Cuers, Elliott, \& Kelly, 1993).

The consequences of growing up in abusive families are well documented. Abused adolescents are more likely to report depressive symptoms (Allen \& Tarnowski, 1989; Mundy, Robertson, Robertson, \& Greenblatt, 1990), experience attachment disorders (Stefanidis, Pennbridge, 
Mackenzie, \& Pottharst, 1992), report symptoms of posttraumatic stress disorder (Kiser, Heston, Millsap, \& Pruite, 1991; Wolfe, Gentile, \& Wolfe, 1989), report higher levels of substance abuse (Dembo et al., 1992; Singer, Petchers, \& Hussey, 1989), and engage in delinquent or other high-risk behaviors (Silbert \& Pines, 1981; Widom \& Ames, 1994) than adolescents from non- abusive backgrounds. Recent research suggests experiencing both physical and sexual abuse has cumulative negative developmental effects over and above experiencing either type of abuse individually (Kurtz et al, 1991).

Patterson, Dishion, and Bank (1984) argued that coercive/abusive families provide "basic training" for antisocial behaviors. Harsh, inconsistent disciplinary practices elicit aggressive responses in children to which the parent typically responds in turn, creating coercive interaction "chains" that often escalate to the use of physical force (Patterson, 1982). These coercive, aggressive interaction styles are learned by children and generalized to other contexts, resulting in academic problems and rejection by conventional peers. Children's subsequent drift into nonconventional peer associations serves to further reinforce coercive interaction styles. Conger et al., (1992) replicated Patterson's findings with adolescent boys and extended the model for adolescent girls (Conger et al., 1993). Mason, Cauce, Gonzales, Hiraga, Grove (1998) have tested aspects of this model with African American families with essentially the same results.

Patterson's social interaction perspective fits well with the processes we have observed in the families of runaways and the subsequent behaviors of runaway adolescents. As adolescents leave or are pushed out of dysfunctional families, interaction patterns learned in the family are carried into early independence. What Patterson et al., (1984) termed "basic training" for antisocial behaviors in the family becomes "advanced training" on the streets. Early interaction processes set up anticipatory attitudes that affect the young person's interpretation of new social relationships and lead to behaviors that confirm these expectations (Caspi, Bem, \& Elder, 1989; Caspi, Elder, \& Bern, 1987).

Intolerable or loosely monitored family situations result in the force out, choice, or "drift" into precocious independence. Often already psychologically harmed and physically victimized, runaway adolescents arrive on the street with expectations that others are hostile and exploitive (Dodge, 1986, Patterson, 1982) and behave in ways that elicit negative/ aggressive responses. This "interactional continuity" (Caspi et al., 1989) serves to corroborate an already negative perception of self and others. Both maladaptive behaviors and negative self-concepts are developmentally perpetuated by the "progressive accumulation of their own consequences" (Caspi et al., 1989, p. 377). Maladaptive behaviors often de- 
manded for survival on the streets evoke negative responses from others. Selected environments reflect the runaway adolescent's self-concept. The runaway comes to believe that he or she does not "need" or "deserve" a supportive family life. This progressive accumulation of interactions and outcomes serves to crystallize and amplify existing psychological distress and personality traits.

\section{Theoretical Model}

This study examined a theoretical model that illustrates the specific mechanisms through which interactional and behavioral continuities result in the progressive accumulation of psychological distress (Figure 1). In the model it was hypothesized that events and behaviors on the streets would exacerbate the effects of earlier family physical and sexual abuse on risk for victimization and depressive symptoms among runaway and homeless adolescents. Family physical and/or sexual abuse was predicted to increase the total time the adolescent has spent in unsupervised settings (e.g., on the streets, living with friends) (Figure 1, Arrow A). A history of family abuse has been found to be associated with the number of times adolescents run away and the total amount of time they have been on the streets since deciding to run (Kufeldt \& Nimmo, 1987; Whitbeck \& Simons, 1990). Further, an abusive family background was predicted to increase the likelihood of deviant peer associations (Arrow B). There is considerable agreement that children from coercive/abusive backgrounds drift into associations with deviant peers. Socially competent children find those from coercive/abusive families difficult to get along with. Rejected by conventional peers these children tend to drift into associations with one another (Dodge, 1983; Patterson, 1982). Direct effects also were hypothesized for family abuse on alcohol and drug use, deviant subsistence strategies (e.g., mugging, burglary, shoplifting), and risky sexual behaviors when on the streets (Arrows C). Numerous studies have linked abuse by parents or caretakers to substance use (Dembo et al., 1992; Singer et al., 1989), deviant subsistence strategies (Whitbeck et al., 1997a; Whitbeck \& Simons, 1990), and high-risk sexual behaviors (Finkelhor, 1984; Janus, Burgess, \& McCormack, 1987; Simons \& Whitbeck, 1991). In turn, positive associations were predicted between nonconventional peer associations and alcohol and drug use, deviant subsistence strategies when on the street, and risky sexual behaviors (Arrows D). This is congruent with studies on problem behavior syndrome that suggest that adolescent problem behaviors are highly correlated and that association with other deviant adolescents is a primary influence in engaging in these activities (Jessor \& Jessor, 1977; Rowe, Rogers, \& Meseck-Bushey, 1989). Because it increases the amount of time at risk for participation in 


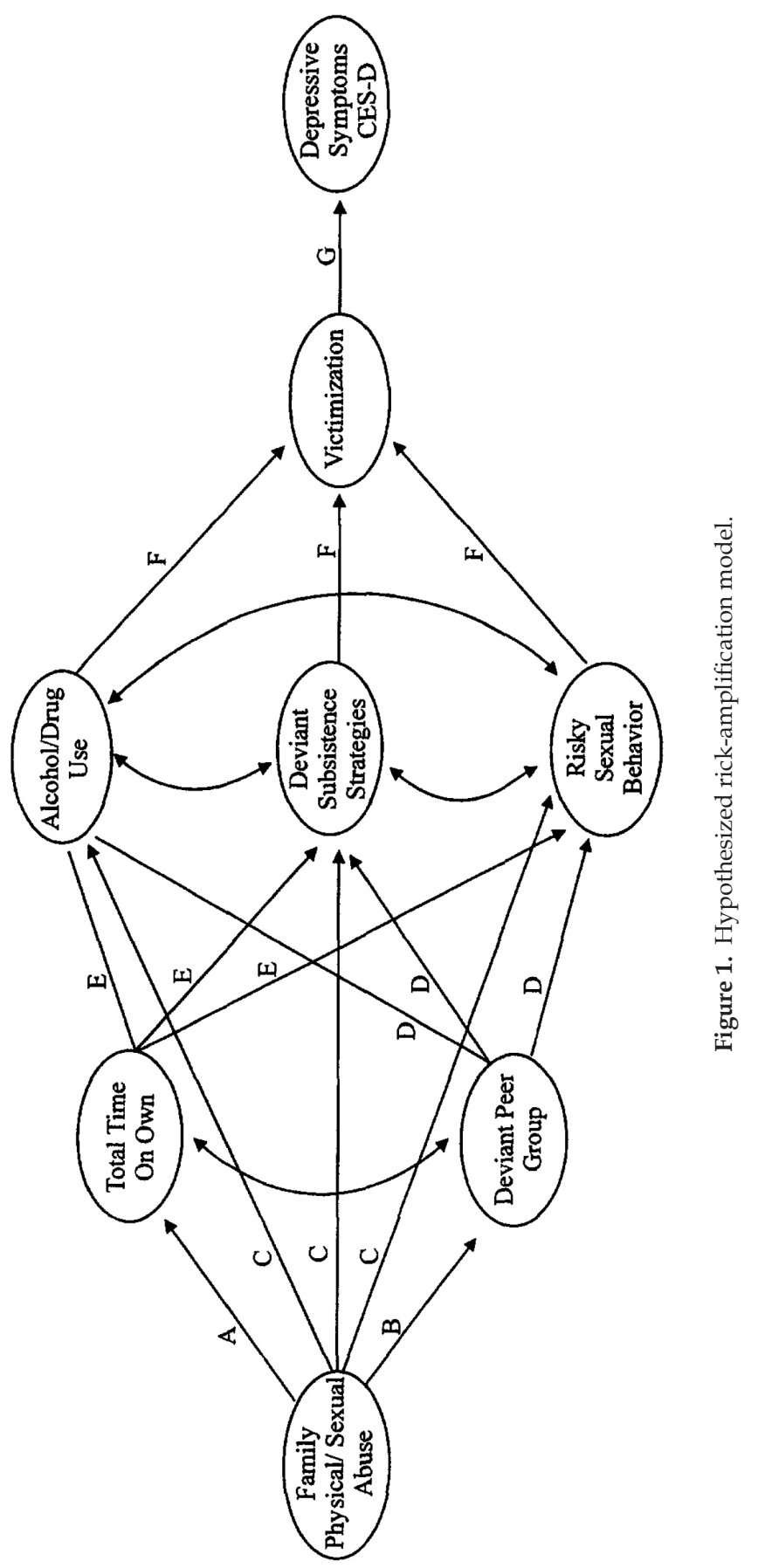


high-risk street behaviors, a positive association was predicted between total time on the street and alcohol/drug use, deviant subsistence strategies, and risky sexual behaviors (Arrows E). Based on other studies of victimization among runaway and homeless adolescents (McCarthy \& Hagan, 1992a, 1992b; Whitbeck et al., 1997a; Whitbeck \& Simons, 1990; 1993), high-risk street behaviors (alcohol and drug use, risky sex, deviant subsistence strategies) were expected to increase risk of serious victimization (e.g. assault, robbery, sexual assault) while the adolescents were on their own (Arrows F). Finally, victimization on the streets was predicted to be strongly associated with depressed affect (Arrow G). Victimization has been linked to increased risk for depressive symptoms in a variety of contexts (Browne \& Finkelhor, 1986; Carmen, Ricker, \& Mills, 1984; Gelles \& Harrop, 1989) including populations of homeless youth (Unger et al., 1997).

\section{Methods}

\section{Sample}

This study was based on the first 255 interviews (102 young men and 153 young women) from an ongoing study of the developmental consequences of homelessness for adolescents. Young people were interviewed on the streets and in shelters by outreach workers affiliated with youth services agencies serving runaway and homeless youth in Missouri, Iowa, Nebraska, and Kansas. Respondents were recruited as part of the participating agencies' regular intake and outreach programs. Referral and support services were offered runaways on the street and provided to youths in shelters by the agencies as part of their outreach programs.

The training of outreach workers as interviewers proved to be a very effective means of contacting and interviewing these difficult to locate youths. In particular, since these adolescents were typically aware of the youth service agency, if not the specific outreach worker, they appeared to be relatively at ease with being interviewed on these topics. Postinterview ratings completed by the interviewers indicated that the youths were generally cooperative and appeared to be responding openly to the survey questions. Agreeing to be interviewed was not a precondition for any of the services the agencies provided and the adolescent received \$15 for his/ her participation.

Interviews lasted about $1 \frac{1}{2}$ hours. Respondents were informed that they could refuse participation, refuse single questions, or stop participating in the interview at any time. They were also informed that reports of abuse by adults must be reported by law and that steps would 
be taken for their protection in the event of disclosure of plans to harm themselves. Interviewers monitored the respondent's attentiveness and provided a break at approximately midpoint in the interview. A snack was provided during this break. Given both the comparatively short administration time, and the break, there was no evidence of a fatigue factor or similar methods effects.*

Response rates for agencies ranged from a low of $81.8 \%$ to a high of $100 \%$. The average response rate across all agencies was $93.5 \%$. The interviews were conducted by five agencies located in four metropolitan areas (Des Moines, Lincoln, St. Louis, and Wichita). The majority of the interviews were conducted in outreach centers or shelters, with less than one in five being a street-intercept interview. The young people ranged in age from 13-20 years with an average age of 16.9 years for young men and 16.2 years for young women. (The means and standard deviations for each of the measures are presented in the margins of the correlation matrix in Table I.) Over one third (36.2\%) of the young women were ages 13 to 15 years and another $41.4 \%$ were either age 16 or 17 . The age distribution for the young men was similar, with $28.8 \%$ ages 13 to 15 and $41.2 \%$ were either 16 or 17 years old.

Given the demographics of the cities in which these interviews were conducted, the sample is quite diverse. Seventy percent of the homeless adolescents were White, 20\% African American, with the remainder Hispanic, American Indian, or Asian. The majority of the young people were from the larger communities. Forty-eight percent reported that they were originally from a city or suburb of a city of 100,000 or more people. Twenty- seven percent said they had lived in cities from 50,000 to 100,000 people. Only $10 \%$ were from very small towns $(2,500$ people or less) or farms or homes in the country.

The adolescents were asked to provide the occupation and educational level of the person they considered their primary caretaker (the person with whom they had lived longest and spent the most time). Thirty percent of the primary caretakers had not completed high school, $21 \%$ were high school graduates, $20 \%$ had some further trade school or college education, and $21 \%$ had a college or trade school degree or higher. Using Dictionary of Occupational Titles (1991) classifications; 18\% of the primary caretakers were managers or professionals; $23 \%$ technical, sales, or administrative support; $25 \%$ service occupations; and $21 \%$ mechanics, construction, or laborers. Although we did not ask the adolescent to estimate family of origin income, $36 \%$ reported caretakers received food stamps at

\footnotetext{
* Additional information regarding the administration of the questionnaire, formatting of the research instrument, and other procedural details may be obtained by request from the senior author.
} 


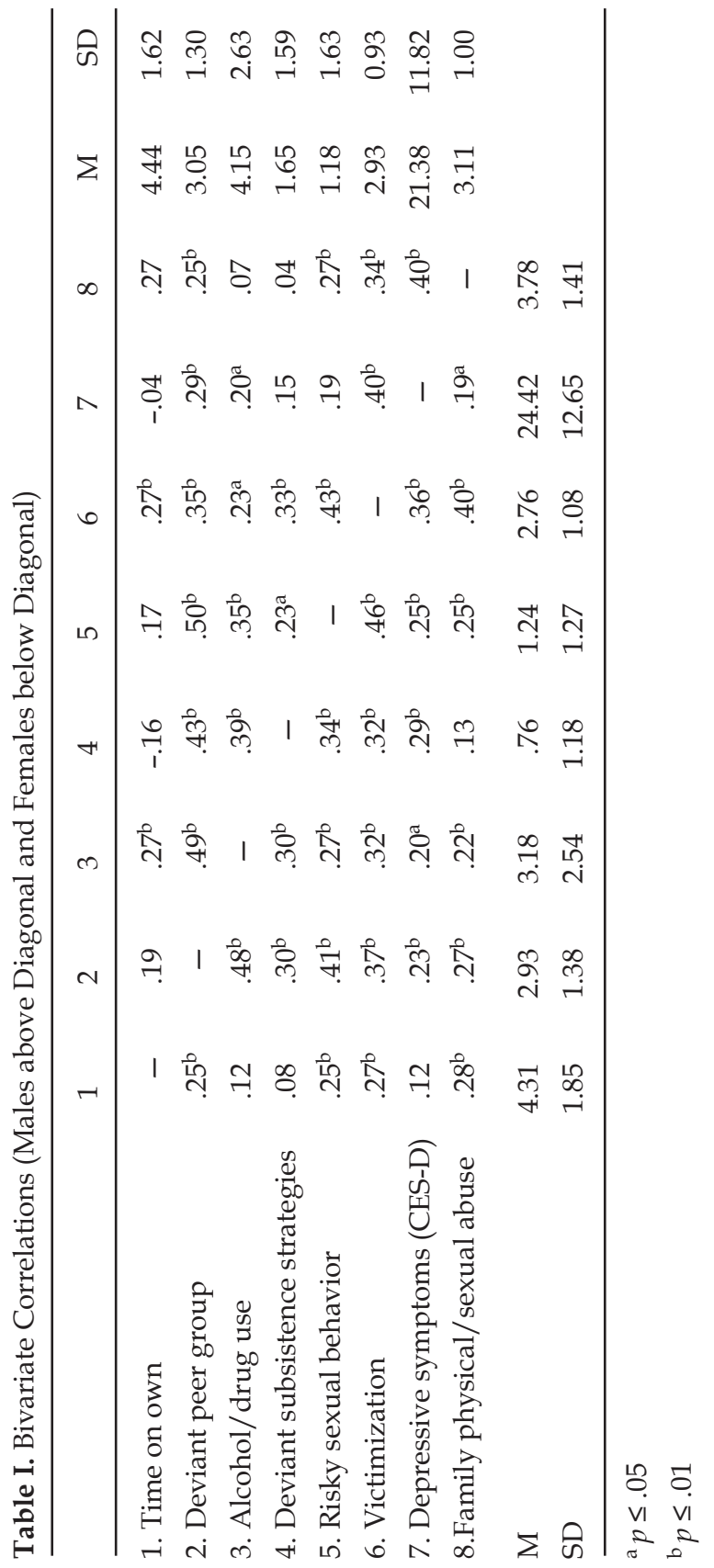


some point when they lived with them, $29 \%$ had been supported by Aid to Families with Dependent Children or "welfare," and 17\% by Social Security or Supplemental Security Income.

At the time of the interview, the young people had been on the street an average of 123 days and on their own (includes street time and unsupervised time when housed) 278 days. On average, they had experienced almost 12 changes in residence and/or living situation and 3 changes in family configuration (e.g., parents divorce, remarried). Parents had initiated changes in their children's residence an average of 1.5 times, while the adolescents initiated change in residence an average of almost 7 times. Agencies/institutions had initiated moves an average of 3 times.

\section{Measures}

The measures used in this study represented a combination of indicators that have been applied to many survey populations (e.g., family abuse, depressive symptoms) and items that were specifically developed for use in studies of homeless adolescents. Where appropriate, measures of internal consistency (e.g., Cronbach's alpha) for the measures have been calculated and reported for this sample. There are no test-retest reliability estimates for the measures given the cross-sectional design used in this study.

Family abuse was measured with 8 items from the Conflict Tactics Scale (Straus \& Gelles, 1990) and 2 additional items asking whether an adult guardian of the child had ever made a verbal request for sexual activity or had forced the child to engage in sexual activity. The 10 items were summed into a single scale. Response categories ranged from 1 (never) to 4 (many times). Cronbach's alpha for the measure was .76 for boys and .77 for girls.

A life events matrix was constructed for each child chronicling moves and changes in family structure. This measure is based on a life calendar technique (Freedman, Thornton, Camburn, Alwin, \& Young-DeMan, 1988) and was developed for this study to provide a detailed accounting of the time these youths had been unsupervised including time on the streets, time in shelters, and in various unsupervised living arrangements. The time on own measure is the logarithm of the total number of days of unsupervised, independent living indicated on the life events matrix.

Affiliation with deviant peers was measured with a checklist asking the adolescent whether any of their close friends had ever engaged in various deviant activities (Whitbeck \& Simons, 1990, 1993). These behaviors included running away, selling or using drugs, being suspended or expelled from school, shoplifting, breaking in to steal items, stealing money, 
threatened or assaulted someone with a weapon, and arrested for a crime. Because some classes of behaviors (e.g., theft-related behaviors) were mentioned several times in the scale and some types only once, items from each class of behavior were standardized to a common metric prior to summing in order to equalize the relative weighting of the various deviant behaviors. Response categories were 1 (yes) or 2 (no). Cronbach's alpha for affiliation with deviant peers was .86 for boys and .87 for girls.

Drug and alcohol use was assessed by the summing 11 items indicating frequency of use of various substances during the past 12 months. The items covered a range of substances including beer, hard liquor, marijuana, cocaine, methamphetamines, amphetamines, opiates, hallucinogens, tranquilizers, barbituates, and inhalants. The actual question wording provided common street names for the various classes of substances. For each of the 11 categories of substances, the youths were asked to report their frequency of use in the past year based on a 7-point scale ranging from never to daily. The responses were summed to create a composite scale. Cronbach's alpha for this scale was .82 for boys and .83 for girls.

Participation in deviant subsistence strategies was assessed with a checklist of 10 items that asked whether the young person had ever sold drugs, panhandled, stole items, broke into places or took items from someone else, shoplifted to get money or food (Whitbeck \& Simons, 1990, 1993). Since there were more measures of some categories of subsistence strategies than others, each grouping of behaviors (e.g., various forms of panhandling or begging) were standardized to a common metric prior to summing to create the scale. Response categories were 1 (yes), and 2 (no). Cronbach's alpha in this sample for this measure was .67 for boys and .64 for girls.

Risky sexual behaviors were measured by 6 items asking the young person whether they had ever traded sex for food, shelter, drugs, or money, associated with other youth who were engaged in these activities, or had thought about exchanging sex for these resources (Whitbeck \& Simons, 1990,1993). This scale measures the degree to which the sexual behaviors and associations of these youth place them at risk for exploitation and abuse.* The measure is not used to assess exposure to sexually transmitted diseases. Response categories were 1 (yes), and 2 (no). Cronbach's alpha for the measure was .80 for boys and .61 for girls. The lower reliability for girls is due to a weaker association between reports of peer behaviors and the other measures in this scale.

* It can be argued that one of the component items, thinking about exchanging sex for food, shelter, drugs, or money is not an appropriate indicator in a risk behavior scale. However, in the present context this measure is thought to tap the youth's tendency to be present or placed in situations or settings that require them to actively consider trading sex for one of these resources. 
Victimization when the adolescent was on his or her own was measured with 8 items that asked whether the young person had ever been beaten, robbed, sexually assaulted, threatened with a weapon, assaulted with a weapon, propositioned to break the law, or deprived of food for a whole day. Response categories ranged from 1 (never) to 4 (many times). Cronbach's alpha for the measure was .71 for boys and .76 for girls.

Depressive symptoms were measured with 20 items from the CESD (Radloff, 1977). The items pertain to feeling low in energy, thoughts of ending one's life, crying easily, feeling hopeless, and so forth. The respondent rates the number of days in the past week they have experienced these symptoms: 0 days, 1-2 days, 2-4 days, 5-7 days. Cronbach's alpha for the measure in this sample was .87 for boys and .90 for girls.

\section{Results}

The Pearson correlation coefficients, $r$, for the measures used in this analysis are presented in Table I. At the bivariate level, family abuse was significantly correlated with both victimization on the street (boys, $r=$ .34; girls, $r=.40$ ) and with depressive symptoms (boys, $r=.40$; girls, $r=$ .19). It also correlated significantly with time on own, association with deviant peers, drug use (girls only), deviant subsistence strategies (girls only), and risky sexual behaviors. Victimization when on the street was significantly correlated with all of the predictor variables in the hypothesized model and with depressive symptoms.

\section{Model for Adolescent Girls}

A structural equation model (SEM) was estimated for adolescent girls (Figure 2) using LISREL VIII (Joreskog \& Sorbom, 1993). Given the sample size and the need to examine the models separately by gender, the models are estimated using the composite scales as indicators for each of the constructs in the theoretical model. Thus, the results are interpretable in the context of standardized ordinary least squares (OLS) regression or path models, with each measure serving as the single indicator of the latent construct. Since the measurement model is fixed, and the model fit is the assessment of the structural model. One of the advantages for using SEM estimation techniques over an OLS approach in the current analysis is that SEM models are particularly well suited for testing for equivalence in parameters across groups. For simplicity of presentation and interpretation, the standardized regression coefficient, $\beta$, is used to describe 


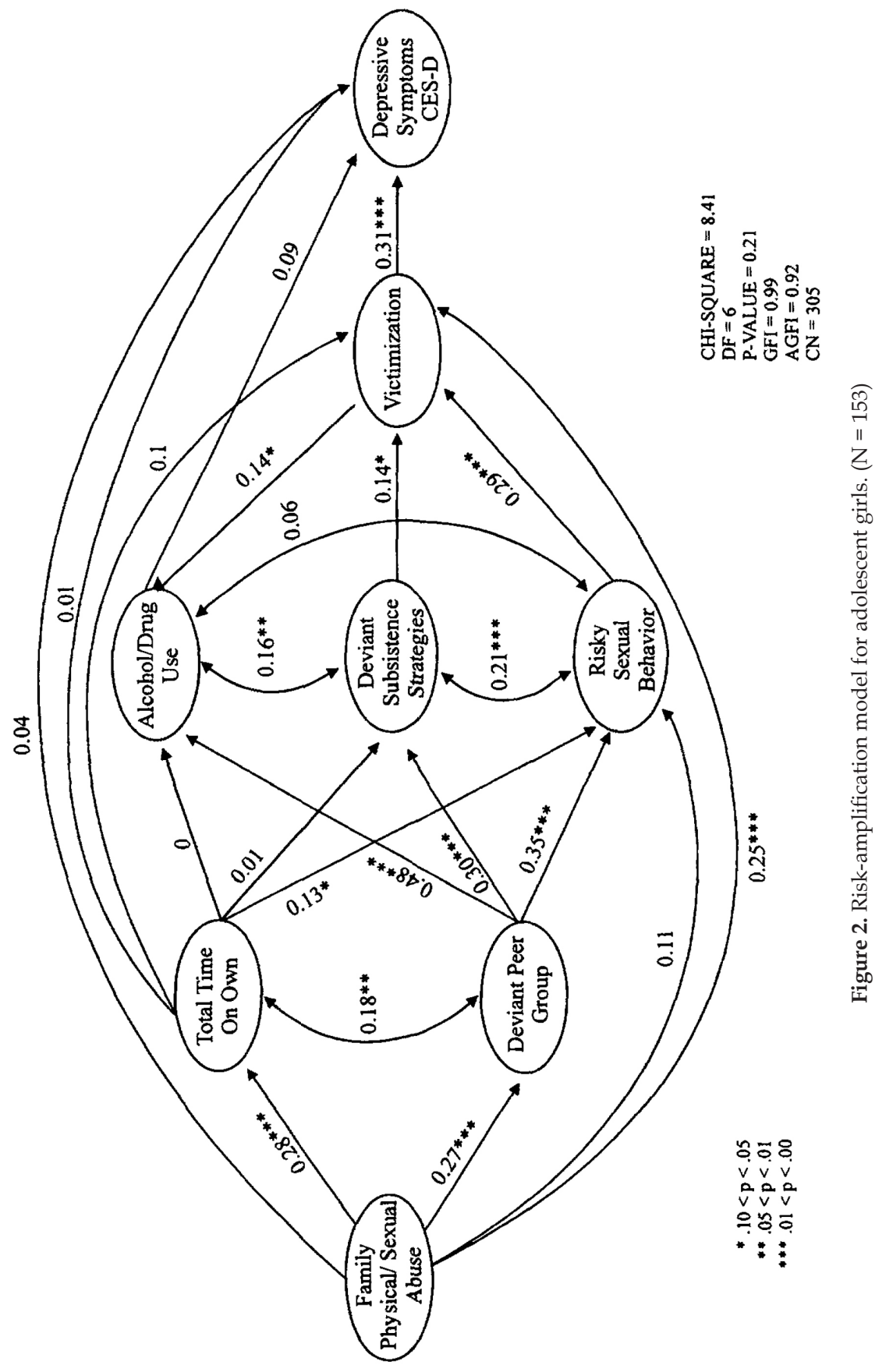


the associations between constructs in these models. The model for girls fit the data very well. The chi-square statistic was nonsignificant, $\chi^{2}(6)=$ $8.41, p=.21$. The adjusted goodness-of-fit index was .92 (Joreskog \& Sorbom, 1993). The critical $\mathrm{N}$ was over $200(\mathrm{CN}=305)$ (Hoelter, 1983). While none of these tests, taken alone or jointly, can be interpreted as confirming the model, meeting the fit criteria across each of the three tests lends support to the hypothesized model (Bollen, 1989).

Family physical and sexual abuse was significantly associated with the total time the young women had been on their own $(\beta=.28)$, their affiliation with deviant peers $(\beta=.27)$, and victimization when on the street $(\beta$ $=.25$ ). Total time on own and association with deviant peers were significantly correlated $(r=.18)$. Total time on own was weakly associated with risky sexual behaviors $(\beta=.13)$. Association with deviant peers, however was related to all of the high-risk behaviors in the model: Alcohol/drug use $(\beta=.48)$, deviant subsistence strategies $(\beta=.30)$, and risky sexual behaviors $(\beta=.35)$. In turn, all of the risky behaviors were associated with victimization when on the streets: Alcohol/drug use $(B=.14)$, deviant subsistence strategies $(\beta=.14)$, and risky sexual behaviors $(\beta=.21)$. Alcohol/drug use and deviant subsistence strategies were significantly correlated $(r=.16)$. as were deviant subsistence strategies and risky sexual behaviors $(r=.21)$. Victimization while on their own was strongly associated with depressive symptoms among runaway and homeless adolescent girls $(\beta=.31)$. The model explained $34 \%$ of the variance of victimization and $14 \%$ of the variance of depressive symptoms.

The $\beta$ parameters presented in Figure 2 represent the direct effects of a given variable on subsequent variables in the path model. LISREL VIII also provides a decomposition of the total effects of a variable into the direct effects and the indirect effects, influences via intervening variables, on the dependent variables in the model (Joreskog \& Sorbom, 1993). The decomposition of the direct and indirect effects for the adolescent girl's path model is presented in Table II. The results indicate that all of the effects of family physical and sexual abuse on girls' depressive symptoms were indirect. The effects of family abuse on high-risk behaviors were indirect via its effects on deviant peers and time on own. This suggests that all of the effects of family abuse on girls' depressive symptoms are transmitted via the mediating effects of the intervening variables in the model (Baron \& Kenny, 1986). However, family abuse had significant direct and indirect effects on victimization when adolescents are on their own, indicating that the influence of early abuse on victimization was manifested both directly and indirectly through the intervening variables. The effects of the intervening variables provide support for our risk-amplification hypothesis of victimization and psychological distress among runaway and homeless adolescents. 


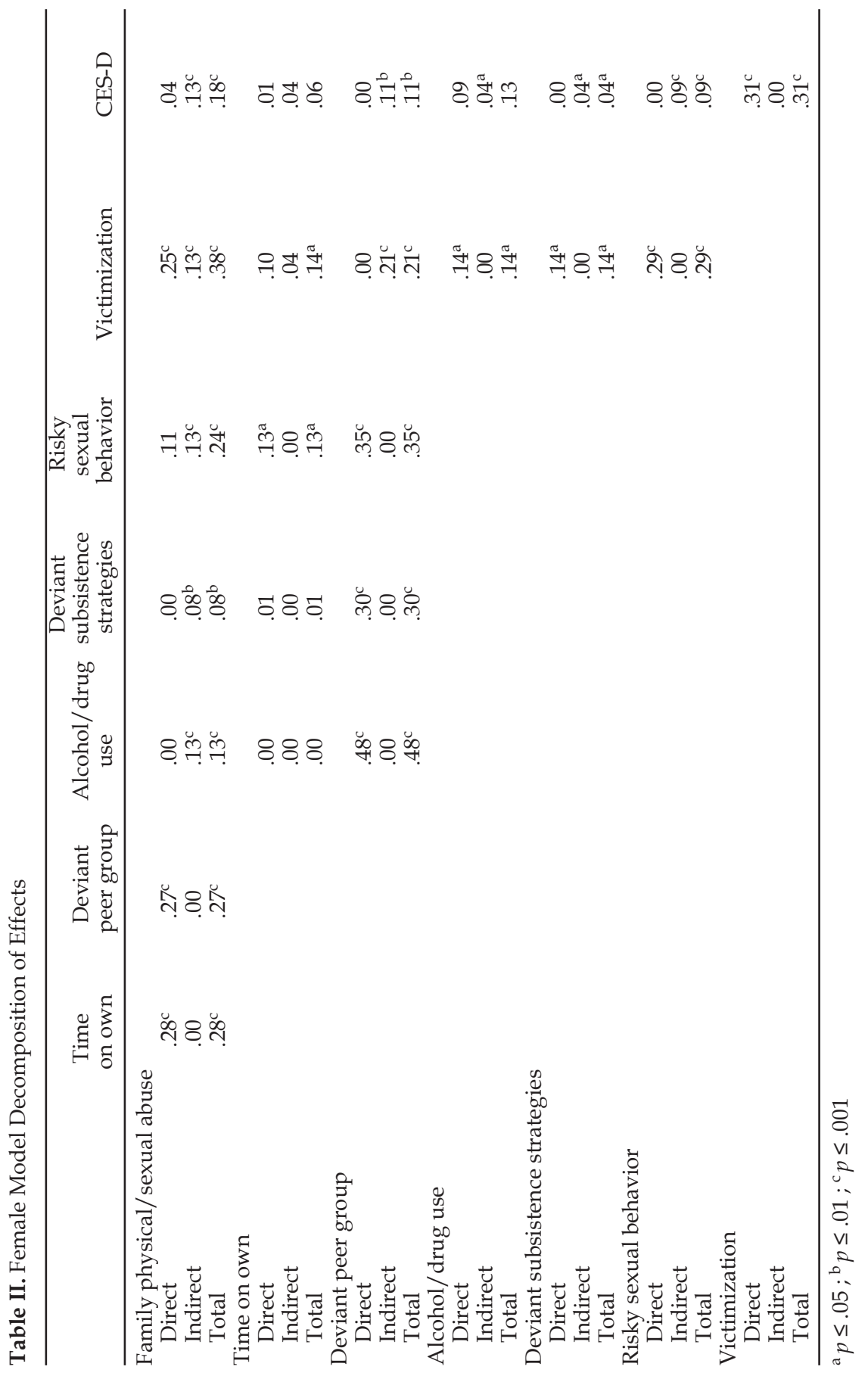


Model for Adolescent Boys

The SEM for adolescent boys (Figure 3) did not fit the data as well as that for girls but was within acceptable limits. Although the chi-square statistic was significant, $\chi^{2}(6)=6.13, p=.04$, the adjusted goodness-offit index was .91 and the critical $\mathrm{N}$ was above $200(\mathrm{CN}=278)$ (Hoelter, 1983).

Family physical and sexual abuse had contrasting effects in the model for adolescent boys compared to the model for girls. Most notably, there were main effects for both victimization $(\beta=.18)$ and depressive symptoms $(\beta=.35)$. Family abuse also directly affected time on own $(\beta=.27)$, affiliation with deviant peers $(B=.25)$, and risky sexual behaviors $(\beta=$ .16). We were puzzled by the negative association between total time on own and deviant subsistence strategies $(\beta=-.25)$. This indicates that the longer the young men are on the street, the less likely they will engage in survival strategies that include victimizing behaviors such as mugging, burglary, and shoplifting. Total time on own was positively associated with alcohol and drug use $(\beta=.18)$ and victimization $(\beta=.25)$. Also noteworthy was the negative association between total time on own and depressive symptoms $(\beta=-.27)$ indicating that the longer the young men are independent, the less depressed they are. As in the girl's model, association with deviant peers was positively related to all of the high-risk behaviors: Alcohol and drug use $(\mathrm{ft}=.46)$, deviant subsistence strategies $(\beta$ $=.48)$, and risky sexual behaviors $(\beta=.45)$. Alcohol and drug use was significantly correlated with deviant subsistence strategies $(r=.22)$. It also had a direct effect on depressive symptoms $(\beta=.17)$. Deviant subsistence strategies was positively associated with victimization on the streets $(\beta$ $=.33)$ as was risky sexual behaviors $(\beta=.28)$. Victimization when on the streets was associated with depressive symptoms $(\beta=.31)$. The model explained $34 \%$ of variance for victimization and $32 \%$ of the variance for depressive symptoms.

Unlike the girl's model where all of the effects of family physical and sexual abuse on depressive symptoms were indirect, in the boy's model, all of the effects of family abuse were direct (Table III). However, for victimization, the effects of family abuse were both direct and indirect, indicating that street experiences had effects over and above those of early family abuse. This suggests that although street experiences did not amplify depressive symptoms for boys over the initial effects of an abusive family background, they did significantly increase risk for victimization outside the family. 


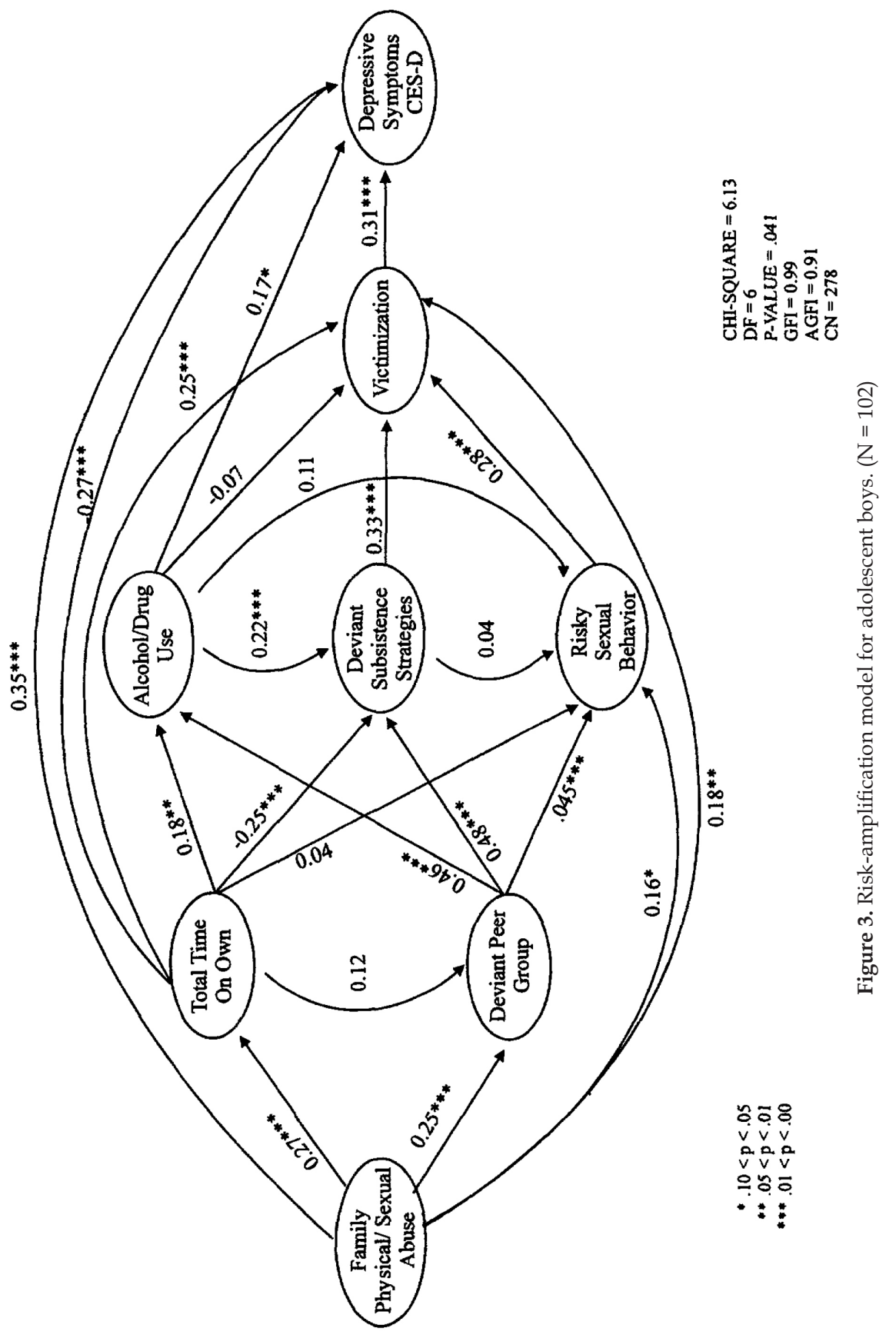




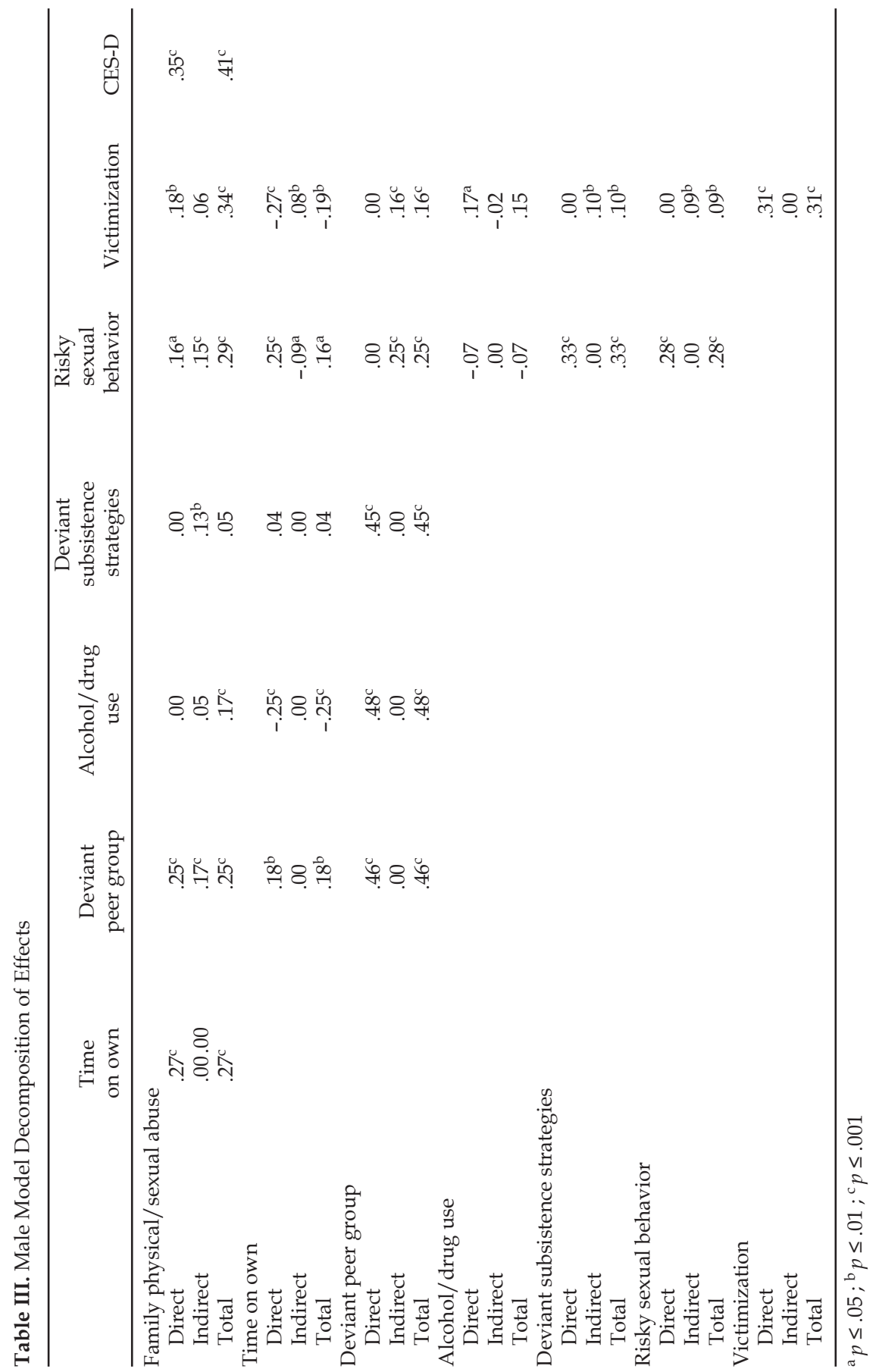




\section{Gender Comparisons}

The models for adolescent boys and girls were compared by estimating the two models simultaneously and restricting the paths in each model to be invariant. These results were then compared to those from a model where the respective paths were allowed to vary across the two groups. The difference in chi-square fit between the two models provides a test of whether or not the restricted path is significantly different across the two groups (Joreskog \& Sorbom, 1993). Three paths differed significantly by gender: (a) the direct path from family abuse to depressive symptoms, (b) the effects of total time on own on deviant subsistence strategies, and (c) the effects of total time on own on depressives symptoms. In each of these paths the effects were significant in the model for adolescent boys and nonsignificant in the model for adolescent girls.

\section{Discussion and Conclusions}

Leaving home makes things worse for troubled young people, but the process appears to vary somewhat by gender. For young women, leaving an abusive home increases likelihood of association with nonconventional peers which, in turn, increases risk for alcohol/drug use, deviant subsistence strategies, and risky sex. All of these behaviors increase the danger of further victimization. Victimization when on their own is strongly related to depressive symptoms. The effects of early family abuse on depressive symptoms are primarily indirect through its consequences for girl's behaviors on the streets.

For young men, however, the effects of early family abuse on depressive symptoms are primarily direct. Although the same pattern emerges as that for young women, for deviant peer associations, alcohol/drug use, deviant subsistence strategies, risky sexual behaviors, and resulting risk of victimization, what happens on the streets does not significantly increase depressive symptoms for young men. The effect of victimization on depressive symptoms when on their own is strong and direct for young men, but not sufficient to achieve statistical significance given the powerful and persistent influence of early family life.

There are two probable explanations for these gender differences. Foremost, is the tendency for young women to have symptoms of internalization and young men to exhibit externalization (Gjerde, Block, \& Block, 1988; Nolen-Hoeksema \& Girgus, 1994). What may be occurring are separate trajectories for young women and men, the former leading to depressed affect and the latter leading to an increase in antisocial traits. A 
second explanation is that the types of victimization to which the young people are exposed are qualitatively different. Young women may be much more at risk for sexual victimization and exploitation once on their own, whereas young men are more at risk for physical victimization and altercations (Hoyt, Ryan \& Cauce, 1997; Whitbeck et al., 1997a; Whitbeck \& Simons, 1993). Sexual exploitation and victimization is more likely to lead to internalizing symptoms such as feelings of helplessness, anxiety, and depression in young women (Finkelhor, 1984), while physical victimization is more likely to lead to an externalizing reciprocal aggressive response among young men.

Our use of cross-sectional data severely limits the strength of our argument for an amplification of effects. However, the decomposition of effects suggests that the intervening variables representing street experiences have significant effects for risk of victimization for both young men and women and significant effects for depressive symptoms among young women. A second limitation is the small sample when separate analyses are performed by gender. That the data were collected at multiple sites, however, lends the results credibility and generalizability. These data also indicate that the processes and risk that occur in Midwestern urban areas are very similar to those in other populations centers where research has been done on homeless youth (Whitbeck et al., 1997a).

The present findings provide support for a risk amplification model for runaway and homeless adolescents. When physically or sexually abused young people reach a threshold of family disorganization or victimization that causes them to be kicked out, drift out, or leave home, an already negative developmental trajectory is accentuated by what they experience when on their own. These results are compatible with Caspi and colleagues conception of "cumulative continuity." Maladaptive family histories and behaviors of the runaways select them into environments that perpetuate negative behaviors and negative interaction styles. Their street experiences help to exacerbate and crystallize those behaviors: "They (maladaptive behaviors) are sustained by the progressive accumulation of their own consequences" (Caspi et al., 1987). From Patterson's (1982) social learning perspective this is "advanced training" for antisocial behaviors and other psychological consequences.

The importance of a risk amplification approach to the early emancipation of adolescents has more to do with the intensity and degree of exposure to risk than the fact that such a process may be expected to exist. The psychological impact of unprotected living has been documented for adults (Goodman, Saxe, \& Harvey, 1991) but not for adolescents. The anxiety of precocious independence, coupled with the exposure to often exploitive deviant peers, high-risk behaviors, and physical victimization exacts an enormous psychological toll. Learning to survive in this envi- 
ronment involves learning to be antisocial. The cumulative negative experiences result in interaction chains that continually reinforce low self-concepts and the untrustworthiness of others. Much more research is needed on the developmental trajectories of youths who have experienced periods of homelessness. Longitudinal data are needed to chart developmental consequences across time.

At the policy level, early intervention programs need to be expanded to reduce potential amplification effects of street experiences on existing psychological and behavioral problems. The exploitation and victimization within the family and on the streets has serious and cumulative developmental consequences. Early interception and intervention is needed to break this cycle. Safe-houses, drop-in centers, and street-based outreach workers may provide early opportunities to intervene in this process. However, it is important to recognize that, by the time that these youths are on the street, they are often characterized by antisocial behaviors and conduct problems. Coupled with precocious independence, this suggests that these youths present a unique set of challenges for traditional intervention approaches. Interventions that address the broader matrix of problems that these youths present and face will have a greater probability of success (Cauce Paradise, Embry, Lohr, \& Wagner, 1997). In particular, interventions need to identify and build on the youths' strengths and independence. Otherwise, they run the risk of having the youths rebel and run again.

\section{References}

Allen, D., \& Tarnowski, K. (1989). Depressive characteristics of physically abused children. Journal of Abnormal Child Psychology, 17, 1-11.

Baron, R., \& Kenny, D. (1986). The moderator-mediator variable distinction in social psychological research: Conceptual, strategic, and statistical considerations. Journal of Personality and Social Psychology, 51, 1173-1182.

Bollen, K. (1989). Structural equations with latent variables, New York: Wiley.

Brown, A., \& Finkelhor, D. (1986) Impact of child sexual abuse: A review of the literature. Psychological Bulletin, 99, 66-77.

Carmen, E., Ricker, P., \& Mills, T. (1984). Victims of violence and psychiatric illness. American Journal of Psychiatry, 141, 378-383.

Caspi, A., Bern, D., \& Elder, G. (1989). Continuities and consequences of interactional styles across the life course. Journal of Personality, 57, 375-406.

Caspi, A., Elder, G., Bern, D., (1987). Moving against the world: Life-course patterns of explosive children. Developmental Psychology, 23, 308-313.

Cauce, A. M., Paradise, M, Embry, L., Lohr, Y., \& Wagner, V. (1997). Homeless youth in Seattle: Youth characteristics, mental health needs, and intensive case management. In M. Epstein, K. Kutash, \& A. Duchnowski (Eds.), Outcomes for children and youth with emotional and behavioral disorders and their families: Programs and evaluation best practices. Austin, TX: Pro-Ed. 
Conger, R., Conger, K., Elder, G., Lorenz, F., Simons, R., \& Whitbeck, L. (1992). A family process model of economic hardship and adjustment of early adolescent boys. Child Development, 63, 526-656.

Conger, R., Conger, K., Elder, G., Lorenz, F., Simons, R., \& Whitbeck, L. (1993). Family economic stress and adjustment of early adolescent girls. Developmental Psychology, 29, 206-219.

Committee on Labor and Human Resources. (1990). Examining the impact of homelessness and dislocation on young people in America. Washington, DC. U.S. Government Printing Office.

Daddis, M., Braddock, D., Cuers, S., Elliott, A., \& Kelly, A. (1993). Personal and family distress in homeless adolescents. Community Mental Health Journal, 29, 413-422.

Dembo, R., Williams, L., Schmeidler, J., Berry, E., Wothke, W., Getreu, A., Wish, E., \& Christensen, C. (1992). A structural model examining the relationship between physical child abuse, sexual victimization, and marijuana/hashish use in delinquent youth: A longitudinal study. Violence and Victims, 7, 41-62.

Dictionary of Occupational Titles, Fourth Edition. (1991). Washington, DC. U.S. Employment Service.

Dodge, K. (1983). Behavioral antecedents of peer social status. Child Development, 54, 13961399.

Dodge, K. (1986). A social information processing model of social competence in children. In M. Perlmuteer (Ed.), Minnesota symposia on child psychology (Vol. 18, pp. 77-125). Hillsdale, NJ: L Erlbaum.

Elder, G. (1997). Life course and human development. In R. Lerner (Ed.), Handbook of child psychology, Volume 1: Theoretical models of human development (pp. 939991). New York: Wiley.

Finkelhor, D. (1984). Child sexual abuse: New theory and research. New York: Free Press.

Finkelhor, D., Hotaling, G., \& Sedlak, A. (1990). Missing, abducted, runaway, and throwaway children in America. Washington, DC: Office of Juvenile Justice and Delinquency Prevention:

Freedman, D., Thornton, A., Camburn, D., Alwin, D., \& Young-DeMarco, L. (1988). The life history calendar: A technique for collecting retrospective data. In C. Clogg (Ed.), Sociological methodology 1988 (pp. 37-68). San Francisco: Jossey-Bass.

Gelles, R., \& Harrop, J. (1989). Violence, battering, and psychological distress. Journal of Interpersonal Violence, 4, 400-420.

Gjerde, P., Block, J., \& Block, J. H. (1988). Depressive symptoms and personality during late adolescence: Gender differences in the externalization-internalization of symptom expression. Journal of Abnormal Psychology, 97, 475-486.

Goodman, L., Saxe, L., \& Harvey, M. (1991). Homelessness as psychological trauma. American Psychologist, 46, 1219-1225.

Hoelter, J. (1983). The analysis of covariance structures: Goodness-of-fit-indices. Sociological Methods and Research, 11, 325-344.

Hoyt, D., Ryan, K., \& Cauce, A. M. (1997). Victimization of homeless youth: An analysis of risk factors over time. Paper presented at the meetings of the Society for Research in Child Development, Washington, DC.

Janus, M., Burgess, A. \& McCormack, A. (1987). Histories of sexual abuse in adolescent male runaways. Adolescence, 22, 405-417. 
Jessor, F., \& Jessor, R. (1977). Problem behavior and psychosocial development. New York: Academic Press.

Joreskog, K., \& Sorbom, D. (1993). LISREL 8: User's reference guide. Chicago: Scientific Software.

Kiser, L., Heston, J., Millsap, P., \& Pruitt, D. (1991). Physical and sexual abuse in childhood: Relationship with post-traumatic stress disorder. Journal of American Academy of Child and Adolescent Psychiatry, 30, 776-783.

Kufeldt, K., \& Nimmo, M. (1987). Youth on the Street: Abuse and neglect in the eighties. Child Abuse and Neglect, 11, 531-543.

Kurtz, P., Kurtz, G., \& Jarvis, S. (1991). Problems of maltreated runaway youth. Adolescence, 26, 544-555.

Mason, C., Cauce, A., Gonzales, N., Hiraga, Y., \& Grove, K. (1998). An ecological model of externalizing in African American Adolescents: No family is an island. Journal of Research on Adolescence, in press.

McCarthy, B., \& Hagan, J. (1992a). Mean streets: The theoretical significance of situational delinquency among homeless youth. American Journal of Sociology, 98, 597-627.

McCarthy, B., \& Hagan, J. (1992b). Surviving on the street: The experiences of homeless youth. Journal of Adolescent Research, 7, 412-430.

Moos, R., \& Moos, B. (1981). Family Environment Scale manual. Palo Alto, CA: Consulting Psychology Press.

Mundy, P., Robertson, M., Robertson, J., \& Greenblatt, M. (1990). The prevalence of psychotic symptoms in homeless adolescents. Journal of the American Academy of Child and Adolescent Psychiatry, 29, 724-731.

Nolen-Hoeksema, S., \& Girgus, J. (1994). The emergence of gender differences in depression during adolescence. Psychological Bulletin, 115, 424-443.

Parker, G., Tupling, H., \& Brown, L. (1979). A parental bonding instrument. British Journal of Medical Psychology, 53, 1-10.

Patterson, G. R. (1982). Coercive family processes. Eugene, OR: Castilia.

Patterson, G., Dishion, T., \& Bank, L. (1984). Family interaction: A process model of deviancy training. Aggressive Behavior, 10, 253-267.

Pennbridge, J., Yates, G., David, T., \& Mackenzie, R. (1990). Runaway and homeless youth in Los Angeles County, California. Journal of Adolescent Health Care, 11, 159-165.

Radloff, L. (1977). The CES-D scale: A self-report depression scale for research in the general population. Applied Psychological Measurement, 1, 385-401.

Robertson, J. (1992). Homeless and runaway youths: A review of the literature. In M. Robertson \& M. Greenblatt (Eds.), Homelessness: A national perspective. New York: Plenum Press.

Rotheram-Borus, M., Parra, M., Cantwell, C., Gwadz, M., \& Murphey, D. (1996). Runaway and homeless youths. In R. DiClemente, W. Hansen, \& L. Ponton (Eds.), Handbook of Adolescent Health Risk Behavior. New York: Plenum Press.

Rowe, D., Rodgers, J., \& Meseck-Bushey, S. (1989). An “epidemic" model of sexual intercourse prevalences for black and white adolescents. Social Biology, 36, 127-145.

Saltonstall, M. (1984). Street youth and runaways on the streets of Boston: One agency's response. Boston: The Bridge, Inc. 
Schweitzer, R., Hier, T., \& Terry, D. (1994). Parental bonding, family systems, and environmental predictors of adolescent homelessness. Journal of Emotional and Behavioral Disorders, 2, 39-45.

Silbert, M., \& Pines, A. (1981). Sexual child abuse as an antecedent to prostitution. Child Abuse and Neglect, 5, 407-411.

Simons, R., \& Whitbeck, L. (1991). Sexual abuse as a precursor to prostitution and victimization among adolescent and adult homeless women. Family Issues, 12, 361-379.

Singer, M., Petchers, M., \& Hussey, D. (1989). The relationship between sexual abuse and substance abuse among psychiatrically hospitalized adolescents. Child Abuse and Neglect, 13, 319-325.

Stefanidis, N., Pennbridge, J., Mackenzie, R., \& Pottharst, K. (1992). Runaway and homeless youth: The effects of attachment history on stabilization. American Journal of Orthopsychiatry, 62, 442-446.

Straus, M., \& Gelles, R. (1990). Physical violence in American Families. Brunswick, NJ: Transaction.

Unger, J. B., Kipke, M. D., Simon, T. R., Montgomery, S. B., \& Johnson, C. J. (1997). Homeless youths and young adults in Los Angeles: Prevalence of mental health problems and the relationship between mental health and substance abuse disorders. American Journal of Community Psychology, 25(3), 371-394.

Whitbeck, L., Hoyt, D., \& Ackley, K. (1997a). Abusive family backgrounds and later victimization among runaway and homeless adolescents. Journal of Research on Adolescence, 7, 375-392.

Whitbeck, L., Hoyt, D., \& Ackley, K. (1997b). Families of homeless and runaway adolescents: A comparison of parent/caretaker and adolescent perspectives on parenting, family violence, and adolescent conduct. Child Abuse and Neglect, 21, 517-528.

Whitbeck, L. B., \& Simons, R. L. (1990). Life on the streets: The victimization of runaway and homeless adolescents. Youth \& Society, 22, 108-125.

Whitbeck, L., \& Simons, R. L. (1993). A comparison of adaptive strategies and patterns of victimization among homeless adolescents and adults. Violence and Victims, 8 , 135-152.

Widom, C., \& Ames, M. (1994). Criminal consequences of childhood sexual victimization. Child Abuse and Neglect, 18, 303-318.

Wolfe, V., Gentile, C., \& Wolfe, D. (1989). The impact of sexual abuse on children: A PTSD formulation. Behavior Therapy, 20, 215-228. 